\title{
High-risk human papillomavirus in non-melanoma skin lesions from renal allograft recipients and immunocompetent patients
}

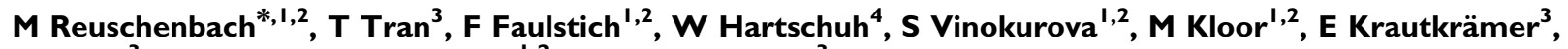 \\ $M Z^{2}{ }^{3}$, M von Knebel Doeberitz ${ }^{1,2}$ and $C$ Sommerer $^{3}$ \\ 'Department of Applied Tumor Biology, Institute of Pathology, University of Heidelberg, Im Neuenheimer Feld 220, Heidelberg 69I 20, Germany; \\ ${ }^{2}$ Clinical Cooperation Unit Applied Tumor Biology, German Cancer Research Center, Im Neuenheimer Feld 220, Heidelberg 69I 20, Germany; \\ ${ }^{3}$ Department of Nephrology, University of Heidelberg, Im Neuenheimer Feld 162. Heidelberg 69120, Germany; ${ }^{4}$ Department of Dermatology, \\ University of Heidelberg, Voßstraße 2, Heidelberg 691 15, Germany
}

BACKGROUND: High-risk human papillomaviruses (HR-HPVs) can be detected in a proportion of non-melanoma skin cancers. Data on prevalence are inconclusive, but are essential to estimate the relevance of HR-HPV, particularly with regard to prophylactic HPV vaccines for skin cancer prevention.

METHODS: High-risk human papillomavirus DNA was investigated in 140 non-melanoma skin lesions from 54 immunocompetent patients and 33 immunosuppressed renal allograft recipients. Expression of pl $6^{\mathrm{INK} 4 \mathrm{a}}$, a marker for HR-HPV oncogene expression in the uterine cervix, and of p53 and pRB was evaluated immunohistochemically.

RESULTS: The highest prevalence of HR-HPV was found in squamous cell cancer (SCC) (46.2\% (6 out of I3) in immunosuppressed and $23.5 \%$ (4 out of 17) in immunocompetent patients). High-risk human papillomavirus positivity was accompanied by diffuse pI $6^{\text {INK4a }}$ expression in most SCC $(P<0.001)$ and basal cell cancers $(P=0.02)$, while almost all SCC in situ were pI $^{\text {INK4a }}$ positive irrespective of HR-HPV presence $(P=0.66)$. Diffuse $p 16^{\mathrm{INK} 4 a}$ expression was associated with lack of $p R B$ expression $(P=0.00 \mathrm{I})$. $\mathrm{p} 53$ was strongly expressed in $40.0 \%$ (56 out of 140) of the lesions irrespective of HR-HPV presence.

CONCLUSION: High-risk human papillomavirus can be detected in lesions of keratinised squamous epithelia. The association of HR-HPV with diffuse p I $6^{\text {INK4a }}$ expression might indicate HR-HPV oncogene expression in a proportion of lesions. Overexpression of p53 suggests p53 pathway alterations in HR-HPV-positive and -negative lesions.

British Journal of Cancer (20I I) I 04, 1334-134I. doi:I0.1038/bjc.201 I.95 www.bjcancer.com

Published online 22 March 2011

(C) 2011 Cancer Research UK

Keywords: human papillomavirus; non-melanoma skin cancer; renal transplantation; immunosuppression; pI $6^{\text {INK4a }}$

Non-melanoma skin cancer (NMSC) is the most frequent cancer type in fair-skinned populations and includes basal cell carcinoma (BCC) and squamous cell carcinoma (SCC) (Madan et al, 2010). The main risk factor is sun exposure, indicating that UV lightinduced mutations have an important role in the carcinogenesis of NMSC (Ramos et al, 2004). Several other factors have been suggested to be involved in NMSC pathogenesis, in particular infectious agents (Nindl and Rosl, 2008). The increased incidence of NMSC in immunosuppressed compared with immunocompetent individuals (Grulich et al, 2007) suggests a central role of the immune system. In the general population, BCC accounts for approximately three fourths and SCC for one fourth of all NMSC cases. Compared with immunocompetent patients, the BCC/SCC ratio shifts towards SCC in renal transplant recipients, and the frequency of multiple, more aggressive lesions is high (Euvrard et al, 2003).

Basal cell carcinomas and SCCs of the skin are both keratinocytederived tumours which show marked differences in clinical and histopathological properties and most likely also in their aetiopathogenesis

*Correspondence: Dr M Reuschenbach;

E-mail: miriam.reuschenbach@med.uni-heidelberg.de

Received 23 December 2010; revised 10 February 2011; accepted 25 February 20I I; published online 22 March $201 \mathrm{I}$
(Madan et al, 2010). Basal cell carcinomas are typically slow growing, locally invasive tumours that rarely metastasise (Rubin et al, 2005). By contrast, SCCs tend to be faster growing, locally invasive tumours with metastatic potential (Alam and Ratner, 2001). The molecular events taking place in BCC and SCC carcinogenesis are most likely heterogenic, and current data argue for a multi-step process frequently involving UV-induced p53 mutations (Boukamp, 2005).

Human papillomavirus DNA of various genotypes has been detected in NMSC (de Villiers et al, 1997), but its role in NMSC carcinogenesis is unclear (Pfister, 2003; Nindl et al, 2007). In 30 to over $80 \%$ of NMSC and their precursor lesions, cutaneous and in particular epidermodysplasia verruciformis-associated HPV types have been detected (Forslund et al, 2003; Iftner et al, 2003; Nindl et al, 2004). Some studies report a higher HPV prevalence in lesions from immunosuppressed patients (Harwood et al, 2000; Stockfleth et al, 2004). Oncogenic high-risk HPV (HR-HPV) types, particularly HPV16, which are causally linked to the development of anogenital cancers and some head and neck cancers (zur Hausen, 2009), have been detected in $2-50 \%$ of NMSC and SCC in situ of the skin (Bowen's disease) (Harwood et al, 2000; Iftner et al, 2003; Nindl et al, 2004). Data on active viral oncogene expression and on differences in HR-HPV prevalence between immunosuppressed and immunocompetent patients are inconclusive. 
Persistent HR-HPV infections can induce malignant transformation of mucosal squamous epithelial cells by inactivation of $\mathrm{p} 53$ and pRB once viral oncogenes E6 and E7 are expressed (Scheffner et al, 1990). High-risk human papillomavirus oncogene expression in cervical squamous epithelium is accompanied by strong nuclear and/or cytoplasmic diffuse overexpression of the cellular cyclindependent kinase inhibitor $\mathrm{p} 16^{\mathrm{INK} 4 \mathrm{a}}$. In contrast, in transiently HR-HPV-infected cervical epithelia, in which HPV oncogene expression is low, no diffuse p16 ${ }^{\mathrm{INK} 4 \mathrm{a}}$ expression is detectable (Sano et al, 1998; Klaes et al, 2001).

We here report evaluation of HR-HPV positivity in multiple invasive NMSC and non-invasive dysplastic epithelial skin lesions (SCC in situ, keratoacanthoma (KA)) from immunosuppressed renal allograft recipients and immunocompetent patients. High-risk human papillomavirus status was correlated with expression of $\mathrm{p} 16^{\mathrm{INR} 4 \mathrm{a}}, \mathrm{pRB}$, and $\mathrm{p} 53$. Gaining more insight into the expression status of cell cycle regulators in association with HR-HPV might help to estimate the relevance of HR-HPV in skin cancer tumour biology in general and particularly in transplant recipients with multiple non-melanoma skin lesions. This is of high relevance for estimating the benefit of prophylactic $\mathrm{HPV}$ vaccination for skin cancer prevention in the immunosuppressed. Besides viral infections, bacterial colonisation has attracted attention in cancer biology and might contribute to carcinogenesis particularly in immunocompromised conditions. Therefore, in addition to HR-HPV DNA prevalence, the presence of Staphylococcus aureus infection in the skin lesions was investigated. A significant association of $S$. aureus infection with SCC of the skin has been recently reported (Kullander et al, 2009). Although a causal role of $S$. aureus infection in development or progression of NMSC is not proven, the finding warrants further investigation, especially in multiple tumours from transplant recipients.

\section{MATERIALS AND METHODS}

\section{Patients and tumour specimens}

A consecutive collection of invasive NMSC and/or non-invasive non-melanoma epithelial skin lesions was obtained from renal allograft recipients treated in the Department of Nephrology at the University Hospital Heidelberg, Germany. Inclusion criteria were age $>18$ years, no history of autoimmune disease requiring additional immunosuppression, no history of other malignancies, at least one renal transplantation, regular follow-up visits at the renal outpatient clinic of the University Hospital Heidelberg, one or more invasive NMSC or non-invasive epithelial skin dysplasia located at non-anogenital sites diagnosed not earlier than 1 year after transplantation, and stable renal allograft function (estimated glomerular filtration rate $(\mathrm{eGFR})>30 \mathrm{ml} \mathrm{min}^{-1}$ ). Invasive NMSC comprised SCC and BCC and non-invasive epithelial skin lesions comprised SCC in situ (also termed as Bowen's disease in the literature), KA, and actinic keratosis.

All renal allograft recipients had regular skin examination for malignoma and non-invasive epithelial skin lesions by a dermatologist at least once per year. Archival formalin-fixed, paraffinembedded tissue of excised NMSC or non-invasive epithelial skin lesions was used in this study.

A cross-sectional cohort of patients with invasive NMSC or noninvasive epithelial skin lesions without known immunosuppression and with regular renal function (eGFR $>80 \mathrm{ml} \mathrm{min}^{-1}$ ) served as controls. These patients were selected from the Department of Dermatology at the University Hospital Heidelberg based on the dermatopathology diagnosis to match the frequencies of different types of lesions with the immunosuppressed cohort.

The institutional Ethics Committee approved the protocol; informed consent was obtained from all enrolled patients.

\section{Microdissection and DNA extraction from tumour tissue}

Formalin-fixed, paraffin-embedded tissue sections were stained with hematoxylin and eosin (H\&E). Neoplastic tissue was morphologically identified under the light microscope and manually microdissected. DNA was extracted using the DNeasy Blood and Tissue kit (Qiagen, Hilden, Germany). The DNA was used for HPV testing and detection of $S$. aureus.

\section{Detection of HR-HPV DNA}

High-risk human papillomavirus detection and genotyping were done using a multiplex test based on the Luminex technology (Multimetrix, Heidelberg, Germany) allowing for standardised detection and typing of the high-risk types HPV16, 18, 31, 33, 35, $39,45,51,52,56,58,59,68,73$, and 82 . PCR was performed using the supplied primers for amplification of HPV L1 (Schmitt et al, $2006)$ and $\beta$-globin to ensure DNA integrity. From samples with negative $\beta$-globin amplification, DNA extraction was repeated from additional tumour sections to increase DNA yield. To monitor potential HR-HPV DNA contamination, formalin-fixed, paraffinembedded tissues from colon adenomas were processed as negative controls throughout the complete procedure from tissue cutting, microdissection, DNA extraction, and genotyping.

\section{Detection of $S$. aureus}

Staphylococcus aureus was detected by PCR amplification of the $S$. aureus nuc gene using previously published primers, forward $5^{\prime}$-GCGATTGATGGTGATACGGTT- $3^{\prime}$ and reverse $5^{\prime}$-AGCCAAGCC TTGACGAACTAAAGC-3', resulting in a 263-bp product (Brakstad et al, 1992; Kullander et al, 2009). PCR products were further analysed by DNA sequencing to confirm the nuc gene sequence.

\section{Immunohistochemistry for $\mathrm{p} 16^{\mathrm{INK} 4 \mathrm{a}}, \mathrm{pRB}$, and p53 expression}

For immunohistochemical analyses, $2 \mu \mathrm{m}$ sections from formalinfixed, paraffin-embedded tissues were used. $\mathrm{p}^{1 \mathrm{INK} 4 \mathrm{a}}$ expression was detected using the CINtec Histology kit (mtm Laboratories, Heidelberg, Germany) according to the manufacturer's instructions. For p53 and pRB staining, antigen retrieval was performed in citrate buffer. Mouse monoclonal antibodies directed against p53 (clone DO-7, Dako, Glostrup, Denmark) and pRB (clone G3-245, BD Pharmingen, Franklin Lakes, NJ, USA) were used. Visualisation was done using the Vectastain Elite ABC kit (Vector Laboratories, Burlingame, CA, USA) and 3,3-diaminobenzidine (DAB) chromogen (Dako). The sections were counterstained with hematoxylin (Dako).

Lesions were categorised according to $\mathrm{p} 16^{\mathrm{INK} 4 \mathrm{a}}$ expression as (a) positive for a diffuse pattern of nuclear and/or cytoplasmic p16 ${ }^{\mathrm{NK} 4 \mathrm{a}}$ expression, beginning in the basal or parabasal layer and variably reaching intermediate and superficial cell layers, in analogy to squamous epithelial lesions at the uterine cervix (Klaes et al, 2001) and (b) negative for a diffuse $16^{\mathrm{INK} 4 \mathrm{a}}$ expression. Lesions classified as negative showed either a focal staining of single epithelial cells or were completely negative for p16 ${ }^{\text {INK4a }}$ expression.

p53 and pRB expression of the lesions were categorised into three groups according to the proportion of tumour cells showing nuclear expression: (1) negative to very low $(<10 \%$ of tumour cells), (2) moderate (10-50\% of tumour cells), and (3) strong ( $>50 \%$ of tumour cells).

\section{Statistical data analysis}

Results were calculated for all analysed skin lesions including all tumours from patients who had multiple tumours. Additionally, 
data from patients who had multiple skin lesions were examined separately. Parametric variables are given as mean \pm s.d., and nonparametric variables as median and range. Frequency distributions are provided for categorical variables. Fisher's exact test or Student's $t$-test was used to test the association between the parameters HPV status, $\mathrm{p} 16^{\mathrm{INK} 4 \mathrm{a}} / \mathrm{p} 53 / \mathrm{pRB}$ protein expression, immune status, age, gender, and sun exposure. Two-sided $P$-values $<0.05$ were considered as statistically significant. Associations were tested for separate strata by Breslow-Day test for homogeneity of odds ratios and Chochran-Mantel-Haenszel test for conditional independence. An association was considered independent from the applied strata when Breslow-Day test and Chochran-Mantel-Haenszel test retrieved $P$-values $>0.05$. Data analyses were carried out using SPSS (v16.0) software (SPSS, Munich, Germany).

\section{RESULTS}

\section{Patient and skin lesion characteristics}

Fifty-four renal allograft recipients with non-melanoma skin lesions recorded in the clinical database fulfilled the inclusion criteria. From 34 patients ( 25 male, 9 female; median age of 67 (44-75) years) with a total number of 79 non-melanoma skin lesions, tumour tissue was available. In addition, 62 nonmelanoma skin lesions from 54 immunocompetent controls (36 male, 18 female; median age $71(43-87)$ years) were included in the present study (Table 1; Figure 1). All immunosuppressed and immunocompetent patients were Caucasian and had skin type Fitzpatrick II or III.

One patient with actinic keratosis was excluded from further analyses. Histology evaluation of the 78 skin biopsies of the remaining 33 immunosuppressed patients revealed 13 invasive SCC, 35 BCC, 24 SCC in situ, and 6 KA. From 54 immunocompetent controls, 17 invasive SCC, 18 BCC, 17 SCC in situ, and $10 \mathrm{KA}$ were analysed. Lesions diagnosed as KA were non-invasive dysplastic squamous cell alterations of the skin. The proportion of lesions affecting sun-exposed skin areas (head and hands) was $78.8 \%$ in the immunocompetent compared with $59.5 \%$ in the immunosuppressed patients.

Median time of non-melanoma skin lesion occurrence in renal transplant recipients was 10.5 years $(1-38)$ after transplantation (SCC 6 years (1-34), BCC 9 years $(2-36)$, SCC in situ 13 years $(2-33)$, and KA 15 years $(1-30))$. Primary immunosuppression and immunosuppressive therapy at the time of the first nonmelanoma skin lesion is included in Table 1. No association between type of non-melanoma skin lesion and immunosuppressive treatment could be detected in the present patient cohort. In all, $51.5 \%$ (17 out of 33 ) immunosuppressed patients had multiple skin lesions ( 9 with 2 or 3 lesions, 6 with $4-6$ lesions, and 2 with 7 lesions) which occurred either synchronously (26 out of 62 lesions) or metachronously ( 36 out of 62 lesions, median time between occurrence of lesions 1.5 years (1-7), included in Figure 2). Most of the patients ( 11 out of $17,64.7 \%$ ) with multiple skin lesions had a history of azathioprine therapy. In the cohort of immunocompetent patients, eight patients had two synchronous lesions.

\section{Frequency of HR-HPV}

Among all 140 analysed skin lesions including lesions from patients with multiple tumours, mucosal HR-HPV DNA was detected predominantly in SCC in situ and SCC with $39.0 \%$ (16 out of 41 ) of SCC in situ and 33.3\% (10 out of 30) of SCC. In all, $20.5 \%$ (9 out of 44 ) of BCC and 6.3\% (1 out of 16) of KA tested HR-HPV positive.

Human papillomavirus DNA was detected in 29.5\% (23 out of 78) of skin lesions from immunosuppressed and in $20.9 \%$
Table I Demographics of renal allograft recipients (immunosuppressed) and immunocompetent patients (median, minimum, and maximum; number and percentage)

\begin{tabular}{|c|c|c|}
\hline & $\begin{array}{l}\text { Renal transplant } \\
\text { recipients } \\
(N=33)\end{array}$ & $\begin{array}{l}\text { Immuno- } \\
\text { competent } \\
\text { controls } \\
(N=54)\end{array}$ \\
\hline Age (years) & $67(44-78)$ & $71(43-87)$ \\
\hline Gender (male, \%) & $24(72.7)$ & $37(68.5)$ \\
\hline Time since transplantation (years) & $10.5(1-38)$ & - \\
\hline Duration of haemodialysis (years) & $3(0-15)$ & - \\
\hline Renal disease (number, \%) & & - \\
\hline Diabetes & $3(9.1)$ & \\
\hline Hypertension & $3(9.1)$ & \\
\hline Glomerulonephritis & $16(48.5)$ & \\
\hline ADPKD & $4(12.1)$ & \\
\hline Others & $7(21.2)$ & \\
\hline Transplantation & & - \\
\hline First (number, \%) & $26(78.8)$ & \\
\hline Second (number, \%) & $6(18.2)$ & \\
\hline Third (number, \%) & I (3.0) & \\
\hline \multicolumn{3}{|l|}{ Renal allograft function } \\
\hline Creatinine $\left(\mathrm{mg} \mathrm{dl}^{-1}\right)$ & $1.18(0.63-2.29)$ & \\
\hline \multicolumn{3}{|l|}{$\begin{array}{l}\text { Immunosuppression at time of transplantation/ } \\
\text { at time of first non-melanoma skin lesion }\end{array}$} \\
\hline Ciclosporin A+Azathioprin+Steroids & $12 / 4$ & \\
\hline Azathioprin+Steroids & $5 / 1$ & \\
\hline Ciclosporin A+Steroids & $5 / 16$ & \\
\hline Ciclosporin A+MMF+Steroids & 9/9 & \\
\hline Tacrolimus+MMF+Steroids & $2 / 3$ & \\
\hline
\end{tabular}

Abbreviations: $\mathrm{ADPKD}=$ autosomal dominant polycystic kidney disease; $\mathrm{MMF}=$ mycophenolate mofetil.

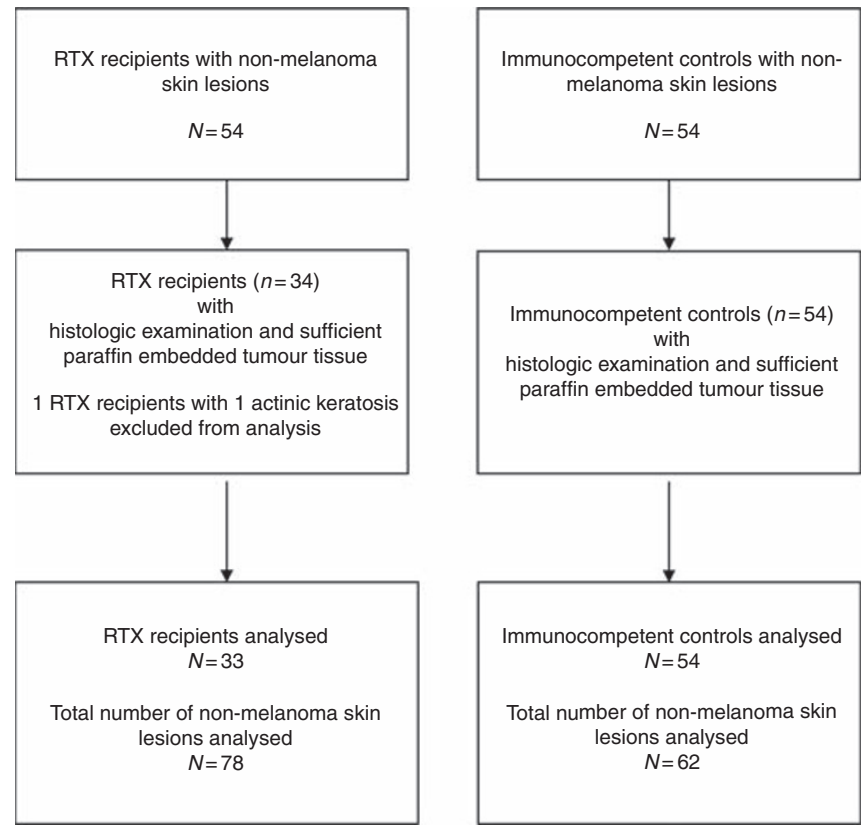

Figure I Study flow chart. RTX = renal transplantation.

(13 out of 62) lesions from immunocompetent individuals (Fisher's exact $P=0.171$ ). Stratification by the dermatopathology diagnosis indicated a comparable HR-HPV prevalence between immunosuppressed and immunocompetent patients in SCC in situ 


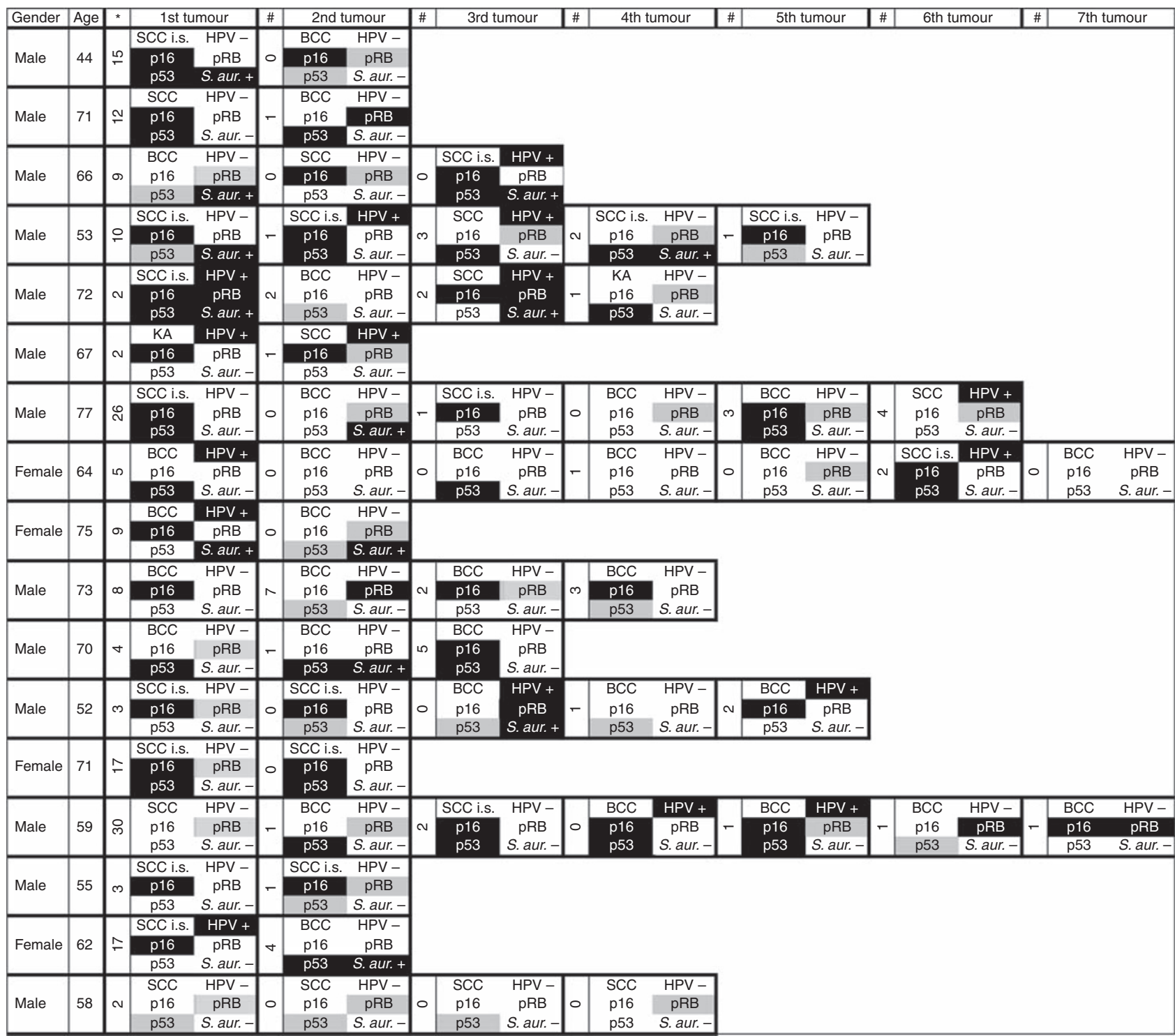

Figure 2 Results of non-melanoma skin lesions from immunosuppressed patients with multiple tumours. Age is given at occurrence of first skin lesion. *Time (years) between first transplantation and first skin lesion. \#Time (years) between occurrence of next skin lesion. Black background indicates positive results for HPV/S. aureus or diffuse/strong expression of $\mathrm{p} 16^{\mathrm{INK} 4 a}$ (diffuse)/pRB (strong)/p53 (strong). Grey background indicates moderate expression of $\mathrm{pRB} / \mathrm{p} 53$. White background indicates negativity. $\mathrm{SCC}=$ squamous cell cancer; $\mathrm{BCC}=$ basal cell cancer; $\mathrm{KA}=$ keratoacanthoma; $\mathrm{SCC}$ i.s. $=\mathrm{SCC}$ in situ; p $16=p^{\prime} 6^{\text {INK4a, }}$ S. aur. = Staphylococcus aureus.

and BCC, but a slightly higher prevalence of HR-HPV in SCC from the immunosuppressed patients (46.2\% (6 out of 13 ) vs $23.5 \%$ (4 out of 17)) (Table 2). High-risk human papillomavirus status in association with immune status was independent from the strata age, gender, and sun exposure. All HR-HPV-positive lesions were genotyped as positive for HPV16. Multiple infections with HR-HPV types 18, 39, 45, and/or 56 together with HPV16 were detected in seven lesions from immunosuppressed patients (three SCC in situ, two SCC, and two BCC) and in one lesion from the immunocompetent group (one SCC) (Table 2).

Most $(52.9 \%$, 9 out of 17) immunosuppressed patients with multiple skin lesions had HPV-negative and HPV-positive tumours. In all, $35.3 \%$ (6 out of 17) had only HPV-negative lesions (Figure 2). One immunocompetent patient with two lesions had one HPV-negative and one HPV-positive lesion. The remaining immunocompetent patients with two lesions $(87.5 \%, 7$ out of 8) had HPV-negative lesions only.

\section{p16 ${ }^{\text {INK4a }}$ expression and correlation with HR-HPV}

A diffuse, continuous pattern of cytoplasmic and/or nuclear p $16^{\mathrm{INK} 4 \mathrm{a}}$ expression arising from basal and parabasal epithelial cells as it is characteristic for HR-HPV-transformed mucosal squamous epithelia was observed in $47.1 \%$ (66 out of 140 ) of skin lesions, with the highest frequency in SCC in situ $(92.7 \%, 38$ out of 41). Most SCC in situ showed diffuse $\mathrm{p} 16^{\mathrm{INK} 4 \mathrm{a}}$ expression beginning in the parabasal cell layer, but no $\mathrm{p} 16^{\mathrm{INK} 4 \mathrm{a}}$ expression in the basal cell layer (Figure 3); 36.7\% (11 out of 30) of the invasive SCC, $30.2 \%$ (16 out of 53 ) of the BCC, and $6.7 \%$ ( 1 out of 15) KA showed a diffuse p16 $6^{\mathrm{INK} 4 a}$ expression pattern (Table 2; Figure 3). Altogether, $86.1 \%$ (31 out of 36) of HR-HPV-positive lesions demonstrated a diffuse $\mathrm{p} 16^{\mathrm{INK} 4 \mathrm{a}}$ expression pattern compared with $33.7 \%$ (35 out of 104) of HR-HPV-negative lesions $(P<0.001)$. In almost all SCC, BCC, and KA lesions with a diffuse p16 ${ }^{\mathrm{INK} 4 \mathrm{a}}$ expression pattern, HPV DNA was detected, whereas 
Table 2 Results of HR-HPV detection, p $16^{\text {INK4a }}$, pRB, p53 expression analysis, and Staphylococcus aureus detection in all I 40 analysed skin lesions from renal transplant recipients and immunocompetent patients

\begin{tabular}{|c|c|c|c|c|c|c|c|c|c|c|c|c|c|c|c|c|}
\hline \multirow[b]{2}{*}{ Total $n$} & \multicolumn{8}{|c|}{ Lesions from renal transplant recipients } & \multicolumn{8}{|c|}{ Lesions from immunocompetent patients } \\
\hline & 24 & & 13 & & 35 & & 6 & & 17 & & 17 & & 18 & & 10 & \\
\hline \multicolumn{17}{|l|}{ HR-HPV } \\
\hline Negative & 15 & 62.5 & 7 & 53.8 & 28 & 80.0 & 5 & 83.3 & 10 & 58.8 & 13 & 76.5 & 16 & 88.9 & 10 & 100.0 \\
\hline 2-3 HPV types & । & 4.2 & 2 & 15.4 & 2 & 5.7 & 0 & 0.0 & 0 & 0.0 & 0 & 0.0 & 0 & 0.0 & 0 & 0.0 \\
\hline$>3$ HPV types & 2 & 8.3 & 0 & 0.0 & 0 & 0.0 & 0 & 0.0 & 0 & 0.0 & । & 5.9 & 0 & 0.0 & 0 & 0.0 \\
\hline \multicolumn{17}{|l|}{$p / 6^{I N K 4 a}$} \\
\hline No expression & I & 4.2 & 0 & 0.0 & 3 & 8.6 & I & 16.7 & 2 & 11.8 & I & 5.9 & 0 & 0.0 & 0 & 0.0 \\
\hline Focal & 0 & 0.0 & 7 & 53.8 & 22 & 62.9 & 4 & 66.7 & 0 & 0.0 & 11 & 64.7 & 12 & 66.7 & 10 & 100.0 \\
\hline Diffuse & 23 & 95.8 & 6 & 46.2 & 10 & 28.6 & I & 16.7 & 15 & 88.2 & 5 & 29.4 & 6 & 33.3 & 0 & 0.0 \\
\hline Strong & I & 4.2 & 0 & 0.0 & 8 & 22.9 & I & 16.7 & I & 5.9 & 0 & 0.0 & 0 & 0.0 & 0 & 0.0 \\
\hline \multicolumn{17}{|l|}{ 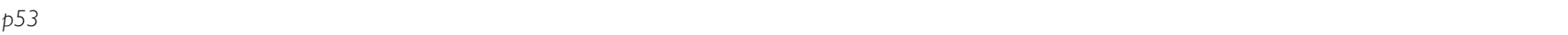 } \\
\hline No expression & 5 & 20.8 & 6 & 46.2 & 12 & 34.3 & 2 & 33.3 & 3 & 17.6 & 4 & 23.5 & 9 & 50.0 & 8 & 80.0 \\
\hline Moderate & 3 & 12.5 & 6 & 46.2 & 10 & 28.6 & 3 & 50.0 & 3 & 17.6 & 6 & 35.3 & 2 & II.1 & 2 & 20.0 \\
\hline Strong & 16 & 66.7 & I & 7.7 & 13 & 37.1 & 1 & 16.7 & 11 & 64.7 & 7 & 41.2 & 7 & 38.9 & 0 & 0.0 \\
\hline \multicolumn{17}{|l|}{ Staphylococcus aureus } \\
\hline Negative & 16 & 16.7 & 9 & 69.2 & 27 & 77.1 & 5 & 83.3 & 9 & 52.9 & 12 & 70.6 & 16 & 88.9 & 6 & 60.0 \\
\hline Positive & 8 & 33.3 & 4 & 30.8 & 8 & 22.9 & I & 16.7 & 8 & 47.1 & 5 & 29.4 & 2 & II.1 & 4 & 40.0 \\
\hline
\end{tabular}

Abbreviations: $\mathrm{SCC}=$ squamous cell cancer; $\mathrm{BCC}=$ basal cell cancer; $\mathrm{KA}=$ keratoacanthoma; $\mathrm{HR}-\mathrm{HPV}=$ high-risk human papillomavirus.

nearly all SCC in situ were $\mathrm{p} 16^{\mathrm{INK} 4 \mathrm{a}}$ positive, irrespective of HR-HPV status (see Table 3 for detailed results).

\section{pRB and p53 expression and relation to HR-HPV and p16 ${ }^{\text {INK4a }}$}

Frequency of $\mathrm{pRB}$ expression is provided in Table 2. In most of the non-melanoma skin lesions positive for a diffuse $\mathrm{p} 16^{\mathrm{INK} 4 \mathrm{a}}$ expression pattern $(n=66)$, no pRB expression was detectable (50 negative, 13 moderate, and 3 strong; $P=0.001$ ).

Strong p53 expression was detected in $40.0 \%$ (56 out of 140) of the analysed skin lesions and particularly frequent in SCC in situ $(65.9 \%, 27$ out of 41$)$. The frequency of strong p53 expression was comparable between immunosuppressed and immunocompetent patients in SCC in situ and BCC, while in invasive SCC the frequency of a strong p53 expression was lower in immunosuppressed than in immunocompetent patients $(7.7 \%$ (1 out of 13$) v s$ $41.2 \%$ (7 out of 17 ), $P=0.04$; Table 2 ). No association between $\mathrm{p} 53$ and $\mathrm{p} 16^{\mathrm{INK} 4 \mathrm{a}}$ expression was observed. In all, $25.7 \%$ of all lesions showed both, diffuse $\mathrm{p} 16^{\mathrm{INK} 4 \mathrm{a}}$, and strong p53 expression; $21.4 \%$ showed a diffuse $\mathrm{p} 16^{\mathrm{INK} 4 \mathrm{a}}$ expression pattern while lacking strong p53 expression; $14.3 \%$ showed strong p53 expression, but no diffuse $\mathrm{p} 16^{\mathrm{INK} 4 \mathrm{a}}$ expression pattern.

Tumours from patients with multiple lesions showed heterogeneity for HR-HPV status, p16 ${ }^{\mathrm{INK} 4 \mathrm{a}}, \mathrm{pRB}$, and $\mathrm{p} 53$ expression (Figure 2).

\section{Staphylococcus aureus infection}

Staphylococcus aureus was detected in $30.6 \%$ (19 out of 62) nonmelanoma skin lesions from immunocompetent and in $26.9 \%$ (21 out of 78) from immunosuppressed patients $(P=0.38)$.
Altogether, $30.0 \%$ (9 out of 30 ) SCC, $18.9 \%$ BCC (10 out of 53 ), $30 \%$ SCC in situ (16 out of 41 ), and $45.5 \%$ (5 out of 11 ) KA were positive for $S$. aureus (Table 2).

\section{DISCUSSION}

Human papillomavirus DNA, including HR-HPV types known to cause anogenital and a proportion of head and neck cancers, has been repeatedly detected in NMSC (de Villiers et al, 1997) and non-invasive epithelial skin lesions. From studies in anogenital and head and neck cancers it is well known that HR-HPV oncogenes, once they are expressed, interact with cellular cell cycle regulators and contribute to uncontrolled cell proliferation, most importantly by degradation of pRB and p53 (Scheffner et al, 1990). p $16^{\text {INK4a }}$ is expressed strongly and continuously in cells undergoing HR-HPV-mediated transformation in epithelia of the uterine cervix. Though the mechanism is not fully clear, there is evidence that a negative feedback mechanism controlling $\mathrm{p} 16^{\mathrm{INK} 4 \mathrm{a}}$ levels in normal cells is disrupted by a reduction of pRB activity in cells expressing HR-HPV oncogene E7 (Khleif et al, 1996). Also some other cancer types, irrespective of the HPV status, show an inverse correlation between pRB and $\mathrm{p} 16^{\mathrm{INK} 4 \mathrm{a}}$ expression levels (Okamoto et al, 1994; Geradts et al, 1995).

In the present systematic explorative study, we demonstrated that mucosal HR-HPV DNA (HPV16) can be detected in keratinised squamous epithelium, at a frequency of $23-46 \%$ in analysed SCC in situ and invasive SCC and $11-20 \%$ in BCC. This finding is in line with previous reports, although frequencies varied between $2 \%$ and $50 \%$, which is most likely due to different HPV detection methods (Harwood et al, 2000; Iftner et al, 2003; Nindl et al, 2004). 

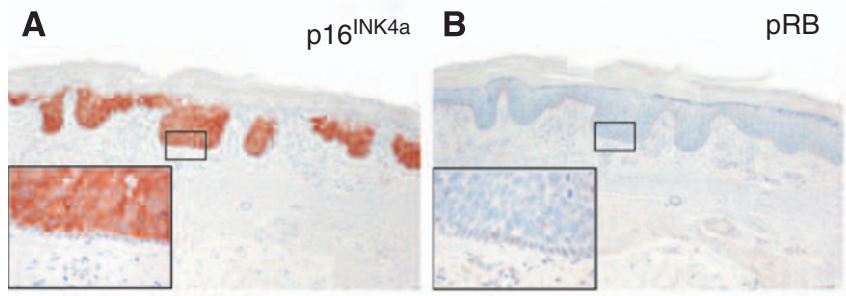

C
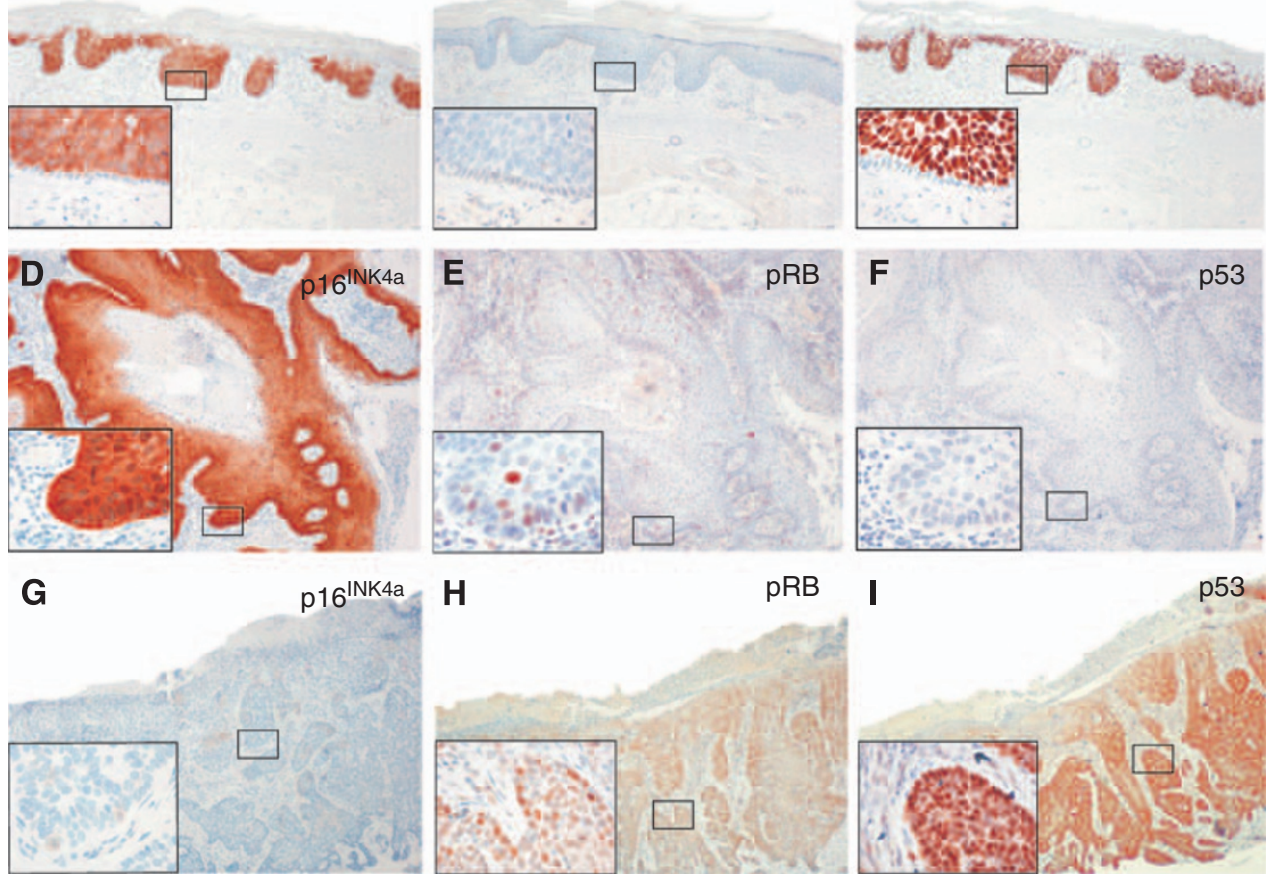

53

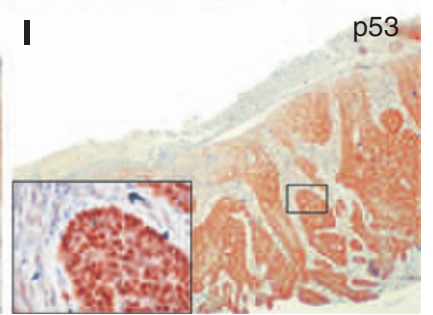

Figure 3 Immunohistochemical staining of serial tissue sections from non-melanoma skin lesions for $p / 6^{\text {INK4a }}$, pRB, and p53. (A-C) HR-HPV-positive SCC in situ with diffuse p I $6^{\text {INK4a }}$ expression pattern $(\mathbf{A})$, absence of pRB expression $(\mathbf{B})$, and strong p53 expression $(\mathbf{C})$. Note the absence of p I $6^{\text {INK4a }}$, pRB, and p53 expression in the basal cell layer of this SCC in situ. (D-F) HR-HPV-positive invasive SCC with diffuse pI $6^{1 N K 4 a}$ expression pattern (D), weak pRB expression (E), and absence of p53 expression (F). (G-I) HR-HPV-negative BCC with absence of diffuse p I 6 IK4a expression, moderate pRB expression, and strong p53 expression.

Table 3 HR-HPV infection and diffuse p $16^{\text {INK4a }}$ expression pattern in non-melanoma skin lesions from renal transplant recipients and immunocompetent controls

\begin{tabular}{|c|c|c|c|c|c|c|c|c|c|c|}
\hline & \multicolumn{5}{|c|}{ Renal transplant recipients NMSC lesions $(N=78)$} & \multicolumn{5}{|c|}{ Immunocompetent controls NMSC lesions $(\mathbf{N}=\mathbf{6 2})$} \\
\hline SCC & 5 & 1 & 1 & 6 & $<0.05$ & 4 & 0 & I & 12 & $<0.001$ \\
\hline $\mathrm{BCC}$ & 4 & 3 & 6 & 22 & 0.06 & 2 & 0 & 4 & 12 & $<0.05$ \\
\hline SCC in situ & 9 & 0 & 14 & 1 & NS & 6 & 1 & 9 & 1 & NS \\
\hline
\end{tabular}

Abbreviations: $\mathrm{SCC}=$ squamous cell cancer; $\mathrm{BCC}=$ basal cell cancer; $\mathrm{KA}=$ keratoacanthoma; HR-HPV = high-risk human papillomavirus; NMSC = non-melanoma skin cancer.

We observed a strong correlation between HR-HPV positivity and diffuse $\mathrm{p} 16^{\mathrm{INK} 4 \mathrm{a}}$ expression in invasive SCC and BCC. Most p16 ${ }^{\mathrm{INK} 4 \mathrm{a}}$-positive lesions lacked pRB expression. Although this observational study cannot formally prove a transforming role of $\mathrm{HR}-\mathrm{HPV}$, the finding of frequent $\mathrm{pRB}$ absence and $\mathrm{p} 16^{\mathrm{INK} 4 \mathrm{a}}$ overexpression in HR-HPV-positive SCC and BCC might suggest a potential relevance of HR-HPV in NMSC. Basal epithelial cells in SCC in situ often lacked $\mathrm{p} 16^{\mathrm{INK} 4 \mathrm{a}}$ and $\mathrm{p} 53$ expression. This finding might be compatible with the assumption that the basal cells are most likely not involved in SCC in situ carcinogenesis (Ishida et al, 2001). Although HR-HPV could be detected in a proportion of SCC in situ, mechanisms other than HR-HPV might cause a nonfunctional $\mathrm{pRB}$ pathway and thus be responsible for $\mathrm{p} 16^{\mathrm{INK} 4 \mathrm{a}}$ overexpression and absence of $\mathrm{pRB}$ expression.

Strong p53 expression was observed in $40 \%$ of the analysed tumours irrespective of HPV status. This observation might suggest presence of mutations in the $p 53$ tumour suppressor gene in these tumours, as p53 overexpression has been linked to certain p53 mutations (Benjamin et al, 2008; Kusters-Vandevelde et al, 2010). However, a high level of detectable p53 protein has also been observed without detectable p53 mutations (Stark et al, 1994).

There is evidence from the literature that p53 overexpression (and p53 mutations) and HR-HPV positivity are inversely correlated in oropharyngeal and vulvar cancer, which led to the classification of molecularly distinct tumour entities (HR-HPV positive/p53 expression negative and HR-HPV negative/p53 expression positive) that also show marked differences in their clinical behaviour (Kruse et al, 2008; Smith et al, 2008), though p53 has also been found strongly expressed in some HR-HPV transformed cancer cells (Cheah and Looi, 2002). Based on our data, there is no correlation between p53 expression and HR-HPV status in epithelial skin lesions. Thus, it may well be that in skin 
carcinogenesis, the HR-HPV oncoprotein-mediated degradation of p53 is not as important as in the pathogenesis of known HRHPV-associated cancers and p53 mutations or other geneticl epigenetic alterations have a primary role in skin carcinogenesis. HPV might then be an additional factor contributing to malignant transformation of the skin. Interestingly, we and others (Blokx et al, 2003; Kusters-Vandevelde et al, 2009) found a lower frequency of p53 overexpression in invasive SSC from immunosuppressed compared with immunocompetent patients. The biological and clinical relevance of this finding needs to be addressed on larger patient cohorts.

The status of $\mathrm{p} 16^{\mathrm{INK} 4 \mathrm{a}}, \mathrm{pRB}$, and $\mathrm{p} 53$ expression was discordant among multiple tumours from the same patient, suggesting varying carcinogenic modes or stages. Inter-tumoural diversity was also found regarding HR-HPV status - most patients with multiple tumours had both, HR-HPV-positive and -negative tumours. Nevertheless, clonality of HR-HPV-positive tumours should be assessed in future studies.

Besides viral infection, bacterial colonisation of the skin might contribute to a higher incidence of skin lesions in the immunosuppressed. The prevalence of $S$. aureus has been reported to be higher in skin SCC than in BCC or normal skin (Kullander et al, 2009). In our cohort, S. aureus DNA was detected in over $30 \%$ of invasive SCC and SCC in situ and, less frequently, in BCC. This also applied to the group of immunosuppressed patients. Presence of $S$. aureus in NMSC might simply indicate an increased susceptibility for bacterial colonisation of neoplastically altered skin. On the other hand, a pathogenetic role of $S$. aureus cannot be excluded, as bacteria might contribute to carcinogenesis by inducing chronic inflammation.

In contrast to the higher prevalence of SCC than BCC reported for transplant recipients (Euvrard et al, 2003), the prevalence of
BCC was higher than SCC in our cohort. Also, patients who were excluded from the study were more likely to have BCC than SCC (data not shown). Regular systematic dermatology evaluations and non-surgical therapy for keratotic skin lesions might explain the relatively low prevalence of invasive SCC in our cohort. Moreover, in our hospital an early low-dose calcineurin inhibitor regimen has been established which might affect tumour prevalence in so far as high-dose calcineurin inhibitor regimens are supposed to increase the risk of especially SCC (Wu et al, 2010).

In summary, we conclude that HR-HPV DNA is detectable in keratinised skin and might contribute to skin cancer pathogenesis in a proportion of lesions. High-risk human papillomavirus prevalence in invasive skin SCC tended to be slightly higher in immunosuppressed than in immunocompetent patients. Further studies are warranted on the relevance of HPV in NMSC carcinogenesis, especially with regard to a potential beneficial effect of prophylactic HPV vaccines in skin cancer prevention, which would be particularly important in organ transplant recipients.

\section{ACKNOWLEDGEMENTS}

We gratefully acknowledge the technical assistance by Sabrina Emmerich, Nina Nelius, Michael Rodrian, Heike Sartor, Lisa Schäfer, and Andrea Weber.

\section{Conflict of interest}

Magnus von Knebel Doeberitz is member of the supervisory board and shareholder of $\mathrm{mtm}$ Laboratories, a company that markets antibodies used in this study. The remaining authors declare no conflict of interest.

\section{REFERENCES}

Alam M, Ratner D (2001) Cutaneous squamous-cell carcinoma. N Engl J Med 344: 975 - 983

Benjamin CL, Melnikova VO, Ananthaswamy HN (2008) P53 protein and pathogenesis of melanoma and nonmelanoma skin cancer. Adv Exp Med Biol 624: $265-282$

Blokx WA, de Jong EM, de Wilde PC, Bulten J, Link MM, Ruiter DJ, van de Kerkhof PC (2003) P16 and p53 expression in (pre)malignant epidermal tumors of renal transplant recipients and immunocompetent individuals. Mod Pathol 16: 869-878

Boukamp P (2005) Non-melanoma skin cancer: what drives tumor development and progression? Carcinogenesis 26: 1657-1667

Brakstad OG, Aasbakk K, Maeland JA (1992) Detection of Staphylococcus aureus by polymerase chain reaction amplification of the nuc gene. J Clin Microbiol 30: $1654-1660$

Cheah PL, Looi LM (2002) P53 immunohistochemical expression: messages in cervical carcinogenesis. Pathology 34: 326-331

de Villiers EM, Lavergne D, McLaren K, Benton EC (1997) Prevailing papillomavirus types in non-melanoma carcinomas of the skin in renal allograft recipients. Int J Cancer 73: 356-361

Euvrard S, Kanitakis J, Claudy A (2003) Skin cancers after organ transplantation. $N$ Engl J Med 348: $1681-1691$

Forslund O, Ly H, Reid C, Higgins G (2003) A broad spectrum of human papillomavirus types is present in the skin of Australian patients with non-melanoma skin cancers and solar keratosis. Br J Dermatol 149: 64-73

Geradts J, Kratzke RA, Niehans GA, Lincoln CE (1995) Immunohistochemical detection of the cyclin-dependent kinase inhibitor $2 /$ multiple tumor suppressor gene 1 (CDKN2/MTS1) product p16INK4A in archival human solid tumors: correlation with retinoblastoma protein expression. Cancer Res 55: 6006

Grulich AE, van Leeuwen MT, Falster MO, Vajdic CM (2007) Incidence of cancers in people with HIV/AIDS compared with immunosuppressed transplant recipients: a meta-analysis. Lancet 370: 59-67

Harwood CA, Surentheran T, McGregor JM, Spink PJ, Leigh IM, Breuer J, Proby CM (2000) Human papillomavirus infection and non-melanoma skin cancer in immunosuppressed and immunocompetent individuals. J Med Virol 61: 289-297

Iftner A, Klug SJ, Garbe C, Blum A, Stancu A, Wilczynski SP, Iftner T (2003) The prevalence of human papillomavirus genotypes in nonmelanoma skin cancers of nonimmunosuppressed individuals identifies high-risk genital types as possible risk factors. Cancer Res 63: 7515-7519

Ishida $\mathrm{H}$, Kumakiri M, Ueda K, Lao LM, Yanagihara M, Asamoto K, Imamura Y, Noriki S, Fukuda M (2001) Comparative histochemical study of Bowen's disease and actinic keratosis: preserved normal basal cells in Bowen's disease. Eur J Histochem 45: 177-190

Khleif SN, DeGregori J, Yee CL, Otterson GA, Kaye FJ, Nevins JR, Howley PM (1996) Inhibition of cyclin D-CDK4/CDK6 activity is associated with an E2F-mediated induction of cyclin kinase inhibitor activity. Proc Natl Acad Sci USA 93: 4350-4354

Klaes R, Friedrich T, Spitkovsky D, Ridder R, Rudy W, Petry U, Dallenbach-Hellweg G, Schmidt D, Knebel Doeberitz M (2001) Overexpression of p16(INK4A) as a specific marker for dysplastic and neoplastic epithelial cells of the cervix uteri. Int J Cancer 92: 276-284

Kruse AJ, Bottenberg MJ, Tosserams J, Slangen B, van Marion AM, van Trappen PO (2008) The absence of high-risk HPV combined with specific p53 and p16INK4a expression patterns points to the HPVindependent pathway as the causative agent for vulvar squamous cell carcinoma and its precursor simplex VIN in a young patient. Int $J$ Gynecol Pathol 27: 591 - 595

Kullander J, Forslund O, Dillner J (2009) Staphylococcus aureus and squamous cell carcinoma of the skin. Cancer Epidemiol Biomarkers Prev 18: $472-478$

Kusters-Vandevelde HV, de Koning MN, Melchers WJ, Quint WG, de Wilde PC, de Jong EM, van de Kerkhof PC, Blokx WA (2009) Expression of p14ARF, p16INK4a and p53 in relation to HPV in (pre-) malignant squamous skin tumours. J Cell Mol Med 13: $2148-2157$

Kusters-Vandevelde HV, Van Leeuwen A, Verdijk MA, de Koning MN, Quint WG, Melchers WJ, Ligtenberg MJ, Blokx WA (2010) CDKN2A but not TP53 mutations nor HPV presence predict poor outcome in 
metastatic squamous cell carcinoma of the skin. Int J Cancer 126: $2123-2132$

Madan V, Lear JT, Szeimies RM (2010) Non-melanoma skin cancer. Lancet 375: $673-685$

Nindl I, Gottschling M, Stockfleth E (2007) Human papillomaviruses and non-melanoma skin cancer: basic virology and clinical manifestations. Dis Markers 23: 247-259

Nindl I, Meyer T, Schmook T, Ulrich C, Ridder R, Audring H, Sterry W, Stockfleth E (2004) Human papillomavirus and overexpression of P16INK4a in nonmelanoma skin cancer. Dermatol Surg 30: 409-414

Nindl I, Rosl F (2008) Molecular concepts of virus infections causing skin cancer in organ transplant recipients. Am J Transplant 8: $2199-2204$

Okamoto A, Demetrick DJ, Spillare EA, Hagiwara K, Hussain SP, Bennett WP, Forrester K, Gerwin B, Greenblatt MS, Serrano M (1994) p16INK4 mutations and altered expression in human tumors and cell lines. Cold Spring Harb Symp Quant Biol 59: 49-57

Pfister H (2003) Chapter 8: human papillomavirus and skin cancer. J Natl Cancer Inst Monogr 31: 52 - 56

Ramos J, Villa J, Ruiz A, Armstrong R, Matta J (2004) UV dose determines key characteristics of nonmelanoma skin cancer. Cancer Epidemiol Biomarkers Prev 13: $2006-2011$

Rubin AI, Chen EH, Ratner D (2005) Basal-cell carcinoma. N Engl J Med 353: $2262-2269$
Sano T, Oyama T, Kashiwabara K, Fukuda T, Nakajima T (1998) Expression status of p16 protein is associated with human papillomavirus oncogenic potential in cervical and genital lesions. Am J Pathol 153: $1741-1748$

Scheffner M, Werness BA, Huibregtse JM, Levine AJ, Howley PM (1990) The E6 oncoprotein encoded by human papillomavirus types 16 and 18 promotes the degradation of p53. Cell 63: 1129-1136

Schmitt M, Bravo IG, Snijders PJ, Gissmann L, Pawlita M, Waterboer T (2006) Bead-based multiplex genotyping of human papillomaviruses. J Clin Microbiol 44: 504-512

Smith EM, Wang D, Rubenstein LM, Morris WA, Turek LP, Haugen TH (2008) Association between p53 and human papillomavirus in head and neck cancer survival. Cancer Epidemiol Biomarkers Prev 17: 421 - 427

Stark LA, Arends MJ, McLaren KM, Benton EC, Shahidullah H, Hunter JA, Bird CC (1994) Accumulation of p53 is associated with tumour progression in cutaneous lesions of renal allograft recipients. $\mathrm{Br} J$ Cancer 70: $662-667$

Stockfleth E, Nindl I, Sterry W, Ulrich C, Schmook T, Meyer T (2004) Human papillomaviruses in transplant-associated skin cancers. Dermatol Surg 30: $604-609$

Wu X, Nguyen BC, Dziunycz P, Chang S, Brooks Y, Lefort K, Hofbauer GF, Dotto GP (2010) Opposing roles for calcineurin and ATF3 in squamous skin cancer. Nature 465: $368-372$

zur Hausen H (2009) Papillomaviruses in the causation of human cancers a brief historical account. Virology 384: 260-265 